We dedicate this volume to the memory of the eminent astrophysicist

\title{
VICTOR AMAZASP AMBARTSUMIAN
}




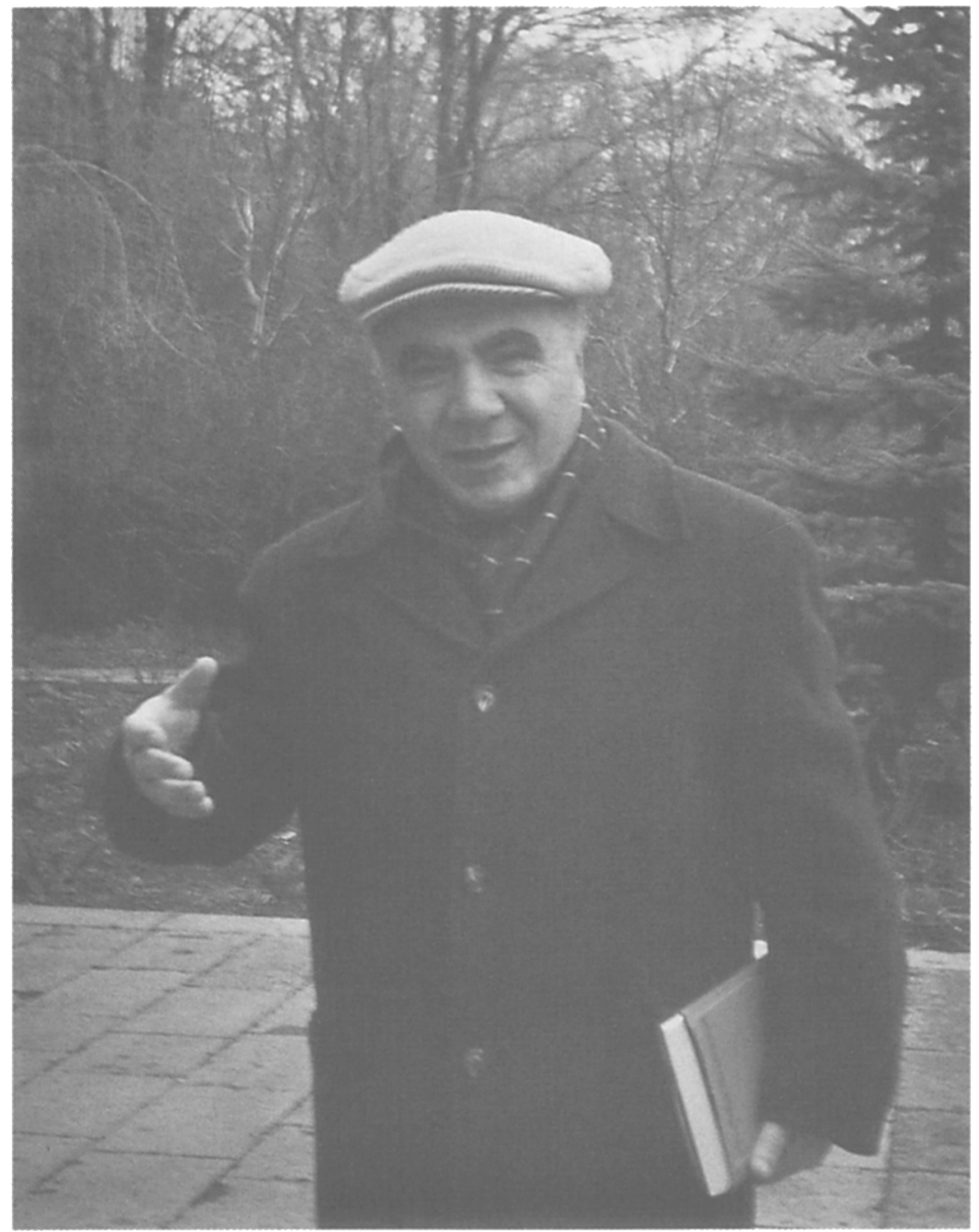

VICTOR AMAZASP AMBARTSUMIAN

1908-1996 


\section{VICTOR AMAZASP AMBARTSUMIAN (1908-1996)}

In a productive career lasting more than 70 years, Victor Amazasp Ambartsumian contributed extensively to the progress of science. His creative research ideas stimulated physics and astrophysics, while his leadership in scientific policy developed and maintained widespread scientific activities in postwar Armenia and abroad.

Ambartsumian was born on September 18, 1908 in Tibilisi, Georgia. He was educated at the University of Leningrad and graduated in 1928. In 1932 he became the head of astrophysics at the same university. He moved to Armenia in 1943 and was one of the founding members of the Armenian Academy of Sciences. In 1946 he founded the Byurakan Astrophysical Observatory and was its director until 1988. In 1947 he became the president of the Armenian Academy of Sciences, a post he retired from in 1993. His scientific works include the physics of gaseous nebulae and radiation transfer theory, the physics of multiple light scattering, the invariance principle, stellar evolution, stellar associations, protostars, and the evolution of galaxies and in particular the study of active galactic nuclei. His work and leadership made the Byurakan Observatory world famous.

His career was rewarded by many honors internationally and within the Soviet Union. He served as President of the IAU from 1961 to 1964, and in 1968 and again in 1970 he was twice elected President of the International Council of Scientific Unions. He was a member of many foreign academies including the U. S. National Academy of Sciences, the Royal Society, and the Academie Franaise. In the Soviet Union among other honors he received five times the Order of Lenin, and the Hammer and Sickle Gold Medal. In 1994 he was proclaimed National Hero of the Republic of Armenia, by then an independent country.

At the age of 80 , Ambartsumian went on a protest fast in Moscow to attract world attention to the conflict in Nagorno-Karabakh. He was a scientist, a leader and a humanitarian. He died in Byurakan on August 12, 1996. 

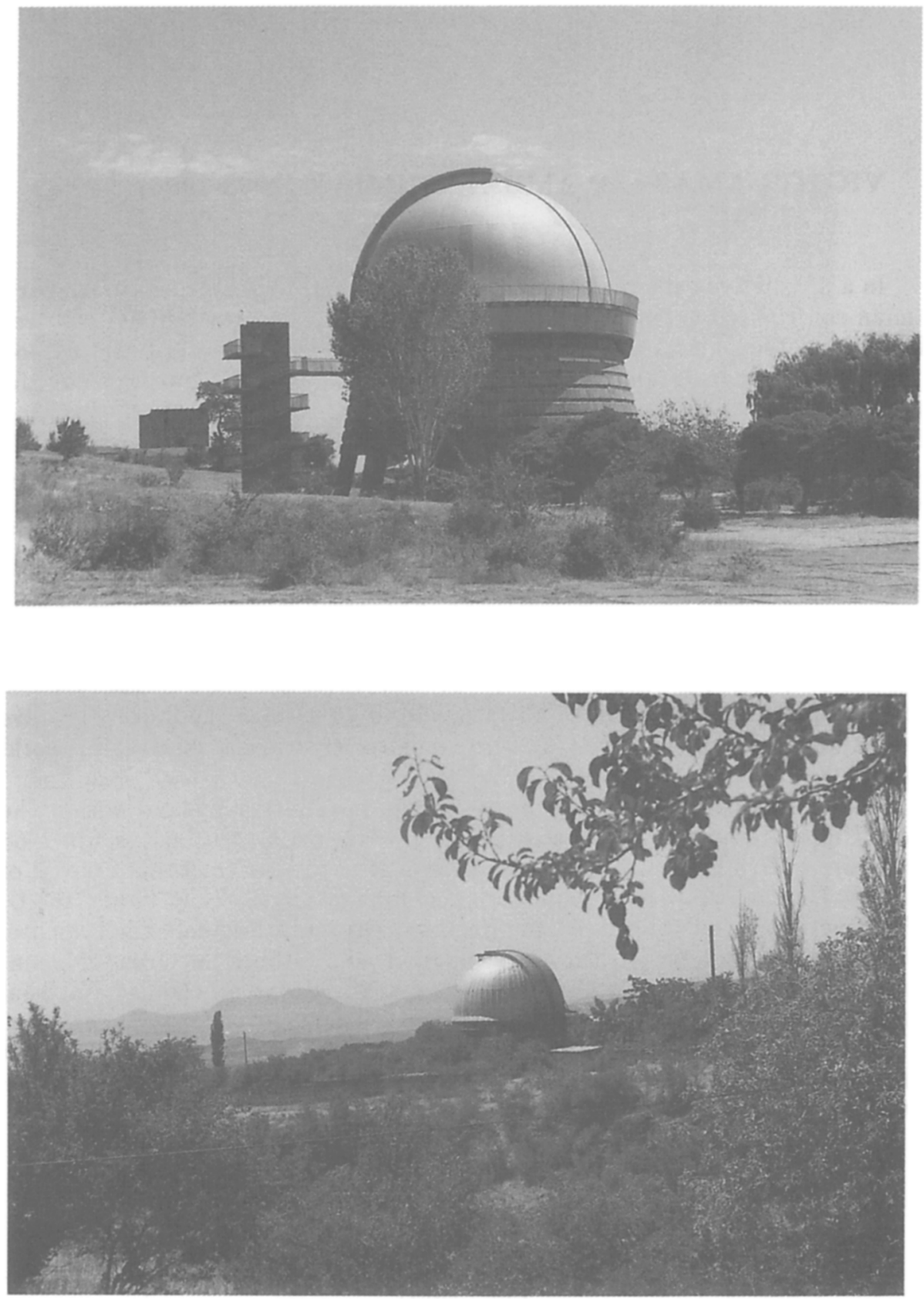

Byurakan and the 2.6 Telescope 